\title{
The Relationship between Voluntary Disclosure and Stock Liquidity of Listed Companies on the Tehran Stock Exchange
}

\author{
Behzad Ghorbani \\ Department of Accounting, Khodabandeh Branch, Islamic Azad University, Khodabandeh, Iran \\ Email: dr.b_ghorbani@yahoo.com \\ Mahdi Salehi
}

Assistant professor of Accounting, Ferdowsi University of Mashhad, Mashhad, Iran

Vahab Rostami

Department of Economics and Social Science, Payame Noor University, PO BOX 19395-3697 Tehran, Iran

Hosein Kazemi

M.A. in Accounting, Takestan Branch, Islamic Azad University, Takestan, Iran

\section{Doi:10.5901/mjss.2015.v6n2p84}

\section{Abstract}

In the present study, the relationship between the amplitude of voluntary disclosure as an external control mechanism, and stock liquidity analyzed in the listed companies on the Tehran Stock Exchange during 2009-2013.Using eliminatory systematic sampling, 80 companies were studied as the research sample. Voluntary disclosure was determined by 71 indicators have also been used in previous studies (Kashanipoor et al., 2009) based on the indicators proposed by Botosan (1997). In order to measure stock liquidity as research by Setayesh et al. (2011), measures of monetary volume of daily stock trading in IRR, average daily turnover of shares, and number of daily transactions of stocks. Research hypotheses have been analyzed using econometric techniques and multiple linear regressions. The results indicate that there is no significant relationship between amplitude of voluntary disclosure and stock liquidity. However, there is a positive and significant relationship between liquidity criteria and firm size and profitability opportunities. In other words, in such companies, stock liquidity is higher than other companies. Research findings are consistent with Hariss (1994) and Branch and Freed (1997), and are inconsistent with the results of Matolscy et al., (2007) and Espinosa et al., (2007) that confirmed the existence of a direct relationship between disclosure and liquidity.

Keywords: voluntary disclosure, stock liquidity, external control mechanisms, Botosan proposed indicators.

\section{Introduction}

Today, accounting could play its key and valuable role in firms of developed countries and demonstrate its capabilities to achieve organizational goals. In Iran, in a transition phase of moving towards industrialization and scientific management, competitive market, and the growing trend of privatization, the importance of accounting information in decision-making and economic decisions is more evident than ever. Rational investors invest based on information available to them. Thus, information is one of the most important tools in investment decisions. To keep investors in financial markets requires the confidential information not to be provided by information disseminators. However, disclosure should be taken place as quickly and simultaneously as possible among all classes of investors. In other words, one of the best mechanisms for reducing information inequalities in the capital market is to eliminate the roots of information inequality (information rent to informed shareholders).Thesis necessary in order to have equal access to confidential information and to establish the equality of company information disseminate among investors, whether major share holders or small shareholders. Due to its extent and depth, there are various tools for investment in any financial market. One of them ajar issues in the investment is liquidity of assets, since some investors may need financial resources of their investments. Liquidity of shares rate is related to trade in stock market by investors. The role of liquidity is crucial in asset valuation, 
since investors are concerned that if they want to sell their assets, whether or not there is a good market for them? This is the risk of asset liquidity in buyers' minds which may discourse agenize stores to invest. The less the liquidity of a share is, the less it is attractive to investors, unless the owner is earning higher return. Experimental evidence shows that the lack of liquidity can play an important role indecision making. In other words, some investors may need financial resources of their investments soon. Liquidity strength can be important in such cases. Liquidity is one of the favorite characteristics of competitive markets. Liquidity is defined as conducting transactions quickly, with minimal cost, and without this veer in flounce on price, and is the main determinant of the viability of the markets. This phenomenon on in futures markets is considered as an important index to evaluate the performance and durability of the markets (Yahiazadehfar, 2008). Given the importance of liquidity as one of the key indicators of performance of financial markets, as well as the importance of understanding the factors affecting this phenomenon to improve the regulation and organization of stock, this research examines the relationship between voluntary disclosure and the stock liquidity in the Tehran Stock Exchange. In this context, the main objective of the current study is to determine whether there is a significant relationship between the level of voluntary disclosure of financial information and liquidity of shares in Iranian companies?

\section{Theoretical Framework and Literature Review}

Belkaoui (2000) argues that disclosure is about information which is useful for the average investor and does not mislead the reader. In an obvious way, the disclosure principle means that no important or interesting data should not be removed or hidden from the average investor. Wolk, et al., (2001) argue that disclosure consists of relevant financial information, including information within and outside financial statements. They also, introduce disclosure of budget information as one of items disclosed outside of financial statements. Kashanipoor et al., (2009) considers the disclosure as an accounting principle based on those financial statements should be prepared full and fair in terms of providing information. This information should be disclosed correctly and sufficiently, so that cover all important items for owners, investors and potential creditors. Usually, when new information is disseminated on the company's status in the market, it is analyzed by analysts, investors and other users, and base on them, decision are made regarding the purchase or sale of shares. This information and how to respond to them affects users 'behavior, particularly actual and potential shareholders, and increases or decreases the stock price and trading volume, since how individuals deal with the recent information forms price validations. Therefore, if information is disseminated heterogeneous and confidential, due to information asymmetry in the capital market, investors show different reactions, which lead to tricky an alyssum the current state of the market. Theory of asymmetric information is particularly important in the financial literature. The foundations in the 1970s by three major economic researchers, George Akerlof, Michael Spence and Joseph Stieglitz were founded. Who won the Nobel Prize in economics in 2001 for his research in the analysis of markets with asymmetric information did receive. Akerlof introduced a product market in which, in current terms, the seller has more information than the buyer. Akerlof scientific hypothesis by showing that the problem of market information may be stopped or the contraction pushes the market to erroneous choice of low-quality products. Accurate and timely dissemination of market information leads to a positive mentality towards equity of the market, and its more stability and consistency. Also, improving market transparency, in turn, increases the competition between market participants, strengthens the relations between market members and investors, and facilitates monitoring and enforcement of laws. According to the efficient market theory, one of the characteristics of efficient and ideal markets is the absence of transaction costs and thus high liquidity. Accounting is one of the information sources that by providing relevant and reliable information can decrease inefficiency of market information, and thereby improves the liquidity of companies' shares. Thus, liquidity of shares can be used as a measure of market performance, particularly with respect to information and be extensively used in the study of factors affecting the provision of useful information. We know that information content is measured by market reaction. In general, the markets show two types of response to information. The first reaction is price effect of information on securities, which is dealt with in most accounting research. However, the market also reacts to information in the form of volume effect. The response is observed as an increase or decrease in supply or demand or the amount of buying and selling shares, which may occur with or without changes in share prices. This effect is reflected in liquidity indicators and is less discussed in accounting literature. Liquidity plays a major role in the price discovery process, and is considered as a measure of market performance, particularly with respect to information (Amihud et al., 2005: 148). Despite the theoretical foundation of this subject, little empirical evidence has been collected, especially in our country, Iran. To reveal the nature of the subject, some previous investigations are mentioned in the following. Botosan (1997) in his study examined the relationship between disclosure and cost of equity. He introduced the disclosure levels in this study as the voluntary disclosure of information by management and providing it in financial statements of the company. 
His study introduced several factors affecting the disclosure level and used them in his study, the most important ones are: number of employees, average salary per employee, inventory, percentage of product sales in the last five years, the market share, units sold, the price of units sold, the growth rate per unit sold. He also divided use of financial analysts into two parts. Companies that use these services more, and those who use small amounts of these services. Finally Botosan in his study concluded that if disclosure level is high in a company, the cost of capital for equity s lower, and vice versa. Moreover, on companies that use the services of financial analysts more than other companies, there is no relationship between the cost of equity and disclosure level. Cormier (1999) tested the impact of human capital voluntary disclosure on information asymmetry between managers and investors. His study indicated that information disclosure about human capital and pension costs reduces asymmetric information of companies, which is more evident about smaller companies.

Mortal and Lipson (2009) in a study examined decisions related to capital structure and the liquidity of the stock market of companies in the United States. They found that when a stock has high liquidity, transaction costs are reduced; and companies that have high liquidity of shares tend to have lower financial leverage. The results of this research are consistent with research by Butler et al., (2005) and Frider and Martel (2006). New empirical findings based on new financial theories (behavioral finance) demonstrated that investors prefer liquid shares due to lower trading costs and are willing to spend more on them. And since there is a relationship between the liquidity of shares and transactions costs, and the cost of capital is a function of the capital structure, therefore liquidity is expected to be effective on capital structure (Mortal and Lipson, 2009: 611). Agarwal (2008) investigated the relationship between liquidity and institutional ownership in terms of mischance and information efficiency. He found a nonlinear relationship between institutional ownership and liquidity. In lower ownership levels, them is chance hypothesis prevails, while increasing the level of institutional ownership, increases liquidity.

Public dissemination of stock shows that the improved liquidity of stock market is affected by the voluntary disclosure. Balakrishnan et al., (2013) examined the effect of voluntary disclosure of companies' information on the liquidity of their shares. Their research sought to reveal a significant relationship between liquidity and voluntary disclosure and firm value. The results show that the voluntary disclosure of information and reduced information asymmetry leads to lower capital costs and higher stock price, resulting in higher firm value. Based on studies and findings on the subject of this study, few similar studies found inside the country that enjoy different criteria for measuring variables other than what is used in this study. However, the results of some relevant research are presented in the following. Kashanipoor et al., (2009) examined the relationship between voluntary disclosure and non-duty managers. The results showed there is no significant relationship between voluntary disclosure and non-duty managers. Fakhari and FallahMohammadi (2009) examined the impact of information disclosure on liquidity of shares of companies in listed Tehran Stock Exchange. The findings of the study indicate that there is a significant inverse relationship between information disclosure and liquidity of equity (the difference between bid and offer prices for shares).

\section{Research Hypotheses}

Previous research suggests that companies tend to disclose information to those markets that are hoping to raise funds with lower fees (Hendrickson and Van Breda1992). Managers are expected to improve the voluntary disclosure at lower cost, and therefore take the chance of opportunistic behavior from major shareholders, and play their role in the liquidity of company shares for public investment well. In this respect, Setayesh et al., (2011) examined the impact of disclosure quality on liquidity and capital cost of companies listed on the Stock Exchange of Tehran. This study, in order to assess the liquidity of shares used measures including monetary volume of daily stock traded in IRR, average daily turnover of shares, and number of daily transactions of shares. The results indicate that there is a significant positive relationship between size of the company and its current and future liquidity. However, there is no significant relationship between the quality of disclosure and current and future liquidity. Moreover, there is a significant negative relationship between the quality of disclosure and capital cost of current and future regular shares. According to the theoretical framework mentioned above, the research hypotheses are formulated as follows:

First hypothesis: There is a significant relationship between the amplitude of voluntary disclosure and monetary volume of daily stock traded.

Second hypothesis: There is a significant relationship between the amplitude of voluntary disclosure and average daily stock turnover.

Third hypothesis: There is a significant relationship between the amplitude of voluntary disclosure and number of daily transactions of shares. 


\section{Methodology}

The research method is descriptive - correlation that examines the effect of voluntary disclosure of information on liquidity of shares of companies listed in Tehran Stock Exchange, and its plan is quasi-experimental using post-event approach. In order to test the research hypothesis, multivariate linear regression based on panel data is used which is a combination of cross-sectional and time-series and using statistical and econometric methods, examines the relationships between variables. In this regard, the study population, according to its purpose and the conditions of its implementation, includes all companies listed on the stock exchange; and due to the goal of generalize ability of findings to all companies of Iran's stock market, proper sampling is objective-based and eliminatory systematic sampling. To remove the effects of confounding variables, previous researchers tried that performing sampling in industries which first have sufficient samples, and second have nature similar to general corporate activities in the stock exchange. The research sample for the period 2009-2013 includes companies which have all the following conditions:

1 - The end of Financial Year of the Company is March 21.

2 - The company from is accepted in Tehran Stock Exchange before 2008.

3 - The company is profitable in the financial period of our study and its stocks are traded at least once.

4 - Company is not a financial intermediation and investment (holding) company.

5 - The annual voluntary disclosure of company's information and all data required in the years 2008 to 2013 are available.

6 - The company has not changed its financial year.

Due to the limitations of the study population, after applying these limitations, the number was about 190 companies, and using a systematic eliminatory sampling, sample of 80 companies was selected purposefully. According to the study time scope, the entire observations include 400 year- company. Library method is used to collect information and data needed to prove the hypotheses were collected using the financial statements of companies included in the statistical population, and are extracted from financial statements contained in the database using the software and Website of the Tehran Stock Exchange. Excel and Eviews version 7 software's are used for data analysis.

\section{Variables and How They are Calculated}

Voluntary disclosure (the independent variable) - to assess the amplitude of the voluntary disclosure of the companies, 71-element Botosan model is used, which was also used in the previous studies (Kashanipoor et al., 2009). The detailed structure of this model (see Appendix A) is based on voluntary disclosure levels as a proportion of the total amount of disclosures.

$$
\mathrm{VD}=\frac{\sum_{\mathrm{j}=1}^{\mathrm{m}} \mathrm{d}_{\mathrm{j}}}{\sum_{\mathrm{j}=1}^{\mathrm{n}} \mathrm{E}_{\mathrm{j}}}=\frac{\text { the number of disclosures }}{\text { the number of all possible disclosures }}
$$

For collecting data related to qualitative variable of voluntary disclosure, the information contained in the report of the Board to the general meeting of shareholders of sample firms is referred which will be extracted from the website (www.rdis.ir).

Liquidity of shares (the dependent variable) - to assess the liquidity of shares of company, the major manifested liquidity tools in previous studies (Setayesh et al. (2011) were also used as follows:

1 - Monetary volume of daily stock traded in IRR: it is one of the most important indicators of boom and recession in the stock market and liquidity in the stock market. In this regard, Barkli et al., (2002) stated that liquidity is affected by the volume and number of stock transaction. In this research, volume of transactions is the value of transactions on a single share in each year of period of the research.

2 - The daily turnover of the company's shares: it is defined as ration of stock turnover as number of shares traded during the research period to the total shares disseminated by the company.

In order to calculate turnover ${ }^{2}$, the following equation is used:

$$
V D=\frac{\sum_{j=1}^{m} d_{j}}{\sum_{j=1}^{n} E_{j}}=\frac{\text { the number of disclosures }}{\text { the number of all possible disclosures }}
$$

Where, Volume $i, d$ is the number of I shares traded in the day $\mathrm{d}$;

Shares out stending $\mathrm{i}_{\mathrm{i}, \mathrm{d}}$ is the number of shares disseminated and sold in the market by the company, and is represented in the company balance sheet as capital stock ${ }^{3}$.

Dayst is the number of days in the month $\mathrm{t}$ when it is possible to trade the stocks.

3 - Number of daily stock transactions: the number of times that a stock is traded in a day.

Bekaert et al., (2007), and Rouwenhorst (1998) and many researchers have used these indicators in their 
research. The turnover ratio calculates frequency of transactions of assets. In other words, the turnover ratio indicates ease of transaction and has a positive relationship with market liquidity. The larger the sales proportion, the higher market liquidity (and vice versa). The disadvantage of sales proportion is that it cannot measure cost of any transaction that is substantially different from an asset to another one. Owing to focus of the criterion on trading volume, assuming a gradual reduction in market liquidity, criterion is likely to be increased while it should be reduced to reflect the decline in market liquidity. However, the turnover ratio has the advantage of simplicity of calculation, and everyone can easily understand it.

Turnover ratio has inverse relationship with difference between the bid and offer prices, since greater secondary criterion leads to a reduction in the frequency of transactions in the stock market.

\section{- The control variables}

A) Profit opportunity: for calculating growth and profit opportunities, the ratio of market value to book value of assets of the company will be used.

Profit opportunity $=\frac{\text { market value }}{\text { book value }}$

B) Firm size: There are several ways to measure the firm size including the number of employees, number of shares issued and the amount of total assets, and finally the log of total assets of companies. To determine the firm size of our sample as one of the control variables, we use total assets of the firm at the end of the period, and to calculate it, we refer to balance sheets of companies in their financial statements which suffice for our purposes.

C) Financial leverage: It seems that by increasing debt levels of companies in their capital composition, the public concern about company's inability to pay debts is increased and managers resort to various strategies to reduce these concerns, including increased level of disclosure and consumer awareness. To assess the level of company's leverage, we use the ratio of debt to equity.

\section{Research Models to Test the Research Hypotheses}

In order to test the research hypotheses and analyze data, we use following regression equations:

1. Regression model for the first hypothesis

VOLDAY $=\beta_{0}+\beta_{1}(\mathrm{VD})+\beta_{2}(\mathrm{MTB})+\beta_{3}(\mathrm{SIZE})+\beta_{4}(\mathrm{LEV})+\varepsilon$

2. Regression model for the second hypothesis

$\mathrm{DTU}=\beta_{0}+\beta_{1}(\mathrm{VD})+\beta_{2}(\mathrm{MTB})+\beta_{3}(\mathrm{SIZE})+\beta_{4}(\mathrm{LEV})+\varepsilon$

3. Regression model for the third hypothesis

$N=\beta_{0}+\beta_{1}(\mathrm{VD})+\beta_{2}(\mathrm{MTB})+\beta_{3}(\mathrm{SIZE})+\beta_{4}(\mathrm{LEV})+\varepsilon$

Where,

VOLDAY is the monetary volume of daily stock traded,

DTU is daily turnover of stocks

$\mathrm{N}$ is the number of daily stock traded

$\mathrm{VD}$ is voluntary disclosure

MTB is profitability opportunity

SIZE is firm size, and

LEV is firm leverage.

In the above models, $\beta$ positive (negative) and significant coefficients indicate that increasing (decreasing) the amplitude of voluntary disclosure, liquidity measures, profitability opportunities, firm size and financial leverage of the firm increases (decreases).

\section{Research Findings}

\subsection{Descriptive Statistics}

Descriptive statistics for variables are presented in Table 1. Comparing the median and the mean and their slight difference represents a normal distribution. According to the fact that analysis of research data is conducted by using panel data technique based on a combination of time-series and cross-sectional data, thus the number of observations is 400 year - company based on a balanced combination of data. 
Table 1. Descriptive indicators of variables

\begin{tabular}{|l|c|c|c|c|c|c|c|}
\hline & VOLDAY & DTU & $\mathrm{N}$ & VD & MTB & SIZE & LEV \\
\hline Mean & 8.50 & 0.31 & 47.98 & 0.51 & 2.77 & 5.99 & 0.58 \\
\hline Median & 8.40 & 0.09 & 12.00 & 0.52 & 2.74 & 5.88 & 0.61 \\
\hline Maximum & 11.04 & 23.22 & 1078 & 1.13 & 3.71 & 8.52 & 0.94 \\
\hline Minimum & 6.04 & 0.00 & 1.00 & 0.15 & 1.14 & 4.29 & 0.04 \\
\hline Std. Dev. & 0.85 & 1.36 & 110.87 & 0.17 & 0.37 & 0.65 & 0.17 \\
\hline Observations & 400 & 400 & 400 & 400 & 400 & 400 & 400 \\
\hline
\end{tabular}

Descriptive analysis of the variables is presented in the table above. The overall look of the average liquidity measures, we find that the liquidity of shares is low and has problems which somewhat affects the market. Minimum volume of daily stock trading in IRR is 6.04and the maximum is 11.04. Minimum daily stock turnover rate is zero and maximum is 23.22 . And the minimum number of daily stock transactions is 1 and maximum is 1078. Therefore the low volume of daily stock trading in IRR, daily stock turnover rate, and number of daily stock transactions reflects the fact that the liquidity of company shares is low. The voluntary disclosure variable descriptive statistics also shows that an average of $51 \%$ of the sample companies voluntarily disseminate their financial information.

\subsection{Testing the equality of the variance}

One of the main assumptions of the classical linear regression model is that disturbing elements have the same variance. If the model has inconsistent variance, $t$ and $F$ statistics give erroneous results. Among the many ways to explore the unequal variance, this research uses Bartlett and Brown - Forsythe test, whose results are presented in Table 2.

Table 2. Results of Bartlett and Brown - Forsythe tests (equality of variance)

\begin{tabular}{|c|c|c|c|}
\hline Method & $\mathrm{df}$ & Value & Probability \\
\hline Bartlett & 4 & 5.295458 & 0.2583 \\
\hline Brown-Forsythe & $(4,395)$ & 1.256838 & 0.2865 \\
\hline
\end{tabular}

Due to the significance level of the test, results indicate equality of variance.

\subsection{Evaluation of co linearity between the independent variables}

To investigate the effect of co linearity on the results, the variance inflation factor (VIF) and tolerances are used. Table 3 shows the results of co linearity between independent variables.

Table 3. Investigation of collinearity between the independent variables

\begin{tabular}{|c|c|c|}
\hline \multirow{2}{*}{ Model1 } & \multicolumn{2}{|c|}{ Co linearity Statistics } \\
\cline { 2 - 3 } & Tolerance & VIF \\
\hline VD & 0.894 & 1.118 \\
\hline MTB & 0.659 & 1.518 \\
\hline SIZE & 0.921 & 1.086 \\
\hline LEV & 0.642 & 1.557 \\
\hline
\end{tabular}

According results of Table 3 , it is observed that VIF statistics indicates non-collinearity between the independent variables in the regression model of the study. The tolerance statistic is also more than 0.4 , which is good.

\section{Results of the Hypotheses Test}

The statistical assumptions related to the first hypothesis are explained as follows:

$\mathrm{HO}$ : there is no significant relationship between amplitude of voluntary disclosure and monetary volume of daily stock traded. 
$\mathrm{H1}$ : there is a significant relationship between amplitude of voluntary disclosure and monetary volume of daily stock traded.

F Limer test - in order to increase the number of observations, raise the degrees of freedom, reduce the variance inequality, and reduce co linearity between variables, panel data techniques are used. It is first necessary to examine the possibility of merging the data and to specify the model fitness is performed in pooled data or panel data. For this purpose, F Limer test is used. In Table 4 the results of this test are presented.

Table 4. Results of $\mathrm{F}$ Limer test to select panel data versus pooled data

\begin{tabular}{lccc}
\hline \hline Effects Test & Statistic & d.f. & Prob. \\
\hline \hline Cross-section F & 3.91 & $(79,316)$ & 0.0000 \\
Cross-section Chi-square & 272.9 & 79 & 0.0000 \\
\hline \hline
\end{tabular}

Model test results indicate that the probability of the test statistic is less than the significance level of 0.05 . The results of this test therefore indicate that the sections studied are heterogeneous, with individual differences therefore, using panel data approach is more appropriate. After ensuring that the model is estimated using panel data, the most important issue is the choice between two methods of fixed effects and random effects. Hausman test is used to determine an appropriate model. Table5 shows the results of this test.

Table 5. Hausman test for selecting fixed effects model versus random effects model

\begin{tabular}{cccc}
\hline \hline Test Summary & Chi-Sq. Statistic & Chi-Sq. d.f. & Prob. \\
\hline \hline Period random & 16.37 & 4 & 0.0026 \\
\hline \hline
\end{tabular}

Hausman test indicates that the probability of the test statistic is less than the significance level of 0.05 . Therefore, to estimate the first research hypothesis model, fixed effects model is used.

After studying the inequality of variance in the linear regression model, the lack of autocorrelation is another important classical assumption. To do this, Durbin - Watson test is used. If the test statistic is in the range 1.5 to 2.5, the lack of correlation between errors is accepted (Momeni, 2007: 129). Table 6 shows the linear regression coefficients and first hypothesis test results for the dependent variable.

Table 6. Results of the first hypothesis tests

\begin{tabular}{ccccc}
\hline \hline \multicolumn{1}{c}{ Variable } & Coefficient & Std. Error & t-Statistic & Prob. \\
\hline \hline C & 1.169591 & 0.686533 & 1.703620 & 0.0894 \\
VD & 0.103421 & 0.286185 & 0.361380 & 0.7181 \\
MTB & 0.806531 & 0.121528 & 6.636590 & 0.0000 \\
SIZE & 0.877260 & 0.086929 & 10.09164 & 0.0000 \\
LEV & -0.170148 & 0.275088 & -0.618522 & 0.5367 \\
\hline \hline R-squared & 0.687007 & Mean dependent var & 8.544344 \\
Adjusted R-squared & 0.682023 & S.D. dependent var & 0.827473 \\
F-statistic & 137.8432 & Durbin-Watson stat & 2.322495 \\
Prob(F-statistic) & 0.000000 & & & \\
\hline \hline
\end{tabular}

Significance test of regression model for the first hypothesis: in order to determine the significance of regression model Fisher F statistic is used. Given the above figure, it is observed that probability of F-statistic is 0.000 , which indicates the significance of the total regression implying that the model is significant in 99 percent significance level.

Evaluation of non-autocorrelation test: According to the results, the Durbin - Watson test statistic (DW) is larger than the coefficient of determination $\mathrm{R}^{2}(0.69>2.32)$, so the possibility of spurious regression is rejected. Also the Durbin Watson test statistic is 2.32, which is between the upper limit and 4 that indicates lack of autocorrelation between the residuals, and on the other hand, in general, values between 1.5 to 2.5 represent a lack of correlation between the errors and the regression can be used. The coefficient of determination is equal to 0.69 that indicates the degree of change in the monetary volume of daily trading of shares in IRR is well explained by the rate of change in the variables included in the regression model of the first hypothesis in linear form. The adjusted coefficient of determination also indicates that 
approximately $68 \%$ of change in dependent variable is explained by independent variables. The coefficients also indicate that there is not a strong correlation between independent variables. In order to determine the significance of the correlation coefficient between the dependent variable and the independent variables, $t$ test was used at error level of 0.05. As we observe, the t-statistic for the intercept is equal to 1.7 and for VD is equal to 0.36 and for LEV is equal -0.62 , all of which are located in the region of non-rejection of the null hypothesis at $95 \%$ level of confidence that indicates their insignificance. The t-statistic for MTB is6.64 and for SIZE is equal to 10.09 , which is located in the region of rejection the null hypothesis that suggests significance of these variables. The sign of coefficient associated with financial leverage (LEV) is negative, i.e. its increase, decreases the monetary volume of daily trading stock values. However, given the significance amount in the last column, it can be found that this value is positive and significant for variable (SIZE) and variable (MTB). The result of first hypothesis test - Regression analysis of the first hypothesis indicate that since the probability of t-statistics between amplitude of voluntary disclosure and monetary volume of daily stock traded in IRR is 0.72and is higher than significant level of 0.05 , the first research hypothesis is rejected. In other words, there is no significant relationship between amplitude of voluntary disclosure and monetary volume of daily stock traded in IRR.

\subsection{The results of the second hypothesis}

The statistical assumptions related to the second hypothesis are explained as follows:

$\mathrm{HO}$ : there is no significant relationship between amplitude of voluntary disclosure and daily stock turnover rate.

$\mathrm{H} 1$ : there is a significant relationship between amplitude of voluntary disclosure and daily stock turnover rate.

Table 7 indicates test results presented in the second research hypothesis.

Table 7. The second hypothesis test results

\begin{tabular}{lcccc}
\hline \hline \multicolumn{1}{c}{ Variable } & Coefficient & Std. Error & t-Statistic & Prob. \\
\hline \hline C & -0.657031 & 0.273990 & -2.398011 & 0.0173 \\
VD & 0.083761 & 0.087194 & 0.960625 & 0.3377 \\
MTB & 0.214485 & 0.040547 & 5.289798 & 0.0000 \\
SIZE & 0.028764 & 0.038558 & 0.746002 & 0.4564 \\
LEV & 0.133740 & 0.094557 & 1.414394 & 0.1586 \\
\hline \hline R-squared & 0.425733 & Mean dependent var & 0.433502 \\
Adjusted R-squared & 0.410945 & S.D. dependent var & 0.542610 \\
F-statistic & 26.78910 & Durbin-Watson stat & 2.088715 \\
Prob(F-statistic) & 0.000000 & & & \\
\hline \hline
\end{tabular}

The second hypothesis test results of study showed that since the probability of $\mathrm{F}$ statistics in the regression model of second hypothesis is 0.000 and less than 0.05 , therefore, the fitted regression model is significant at the $99 \%$ level of confidence. The average coefficient is approximately equal to 0.43 , which shows the variation at included in the regression model assumptions is described linearly, and only $43 \%$ of the variability is explained by the independent variables in the second hypothesis. The examination of the autocorrelation problem in second hypothesis variables suggests that Durbin - Watson statistic is 2.09 , which shows the residuals autocorrelation problem exists. Sign of the coefficient related to intercept is negative and is significant at error level of 0.05 . On the other hand, the dependent variable of daily stock turnover rate has a positive and significant linear relationship in 0.05 levels and the variable of profitability opportunities (MTB). The daily stock turnover rate in the multiple regression analysis does not have a significant linear relationship with the variables of voluntary disclosure (VD), firm size (SIZE) and firm leverage (LEV). The second hypothesis test result - Regression analysis of the second hypothesis indicated that since the range of t-statistics between voluntary disclosure and daily stock turnover rate is 0.34 and is higher than significant level of 0.05 , therefore, the second research hypothesis is rejected. In other words, there is no significant relation between the amplitude of voluntary disclosure and daily stock turnover rate.

\subsection{Test results of the third hypothesis}

The statistical assumptions related to the third hypothesis are explained as follows:

$\mathrm{HO}$ : there is no significant relationship between amplitude of voluntary disclosure and the number of daily stock transactions. 
$\mathrm{H1}$ : there is a significant relationship between amplitude of voluntary disclosure and the number of daily stock transactions.

Table 8 indicates test results presented in the third research hypothesis.

Table 8. The third hypothesis test results

\begin{tabular}{lcccc}
\hline \hline \multicolumn{1}{c}{ Variable } & Coefficient & Std. Error & t-Statistic & Prob. \\
\hline C & -204.5388 & 32.26469 & -6.339400 & 0.0000 \\
VD & 2.597045 & 7.019726 & 0.369964 & 0.7117 \\
MTB & 4.356824 & 2.471402 & 1.762896 & 0.0789 \\
SIZE & 35.74295 & 5.317804 & 6.721374 & 0.0000 \\
LEV & -2.893812 & 7.118150 & -0.406540 & 0.6846 \\
\hline \hline R-squared & 0.694927 & Mean dependent var & 71.49718 \\
Adjusted R-squared & 0.690069 & S.D. dependent var & 72.13975 \\
F-statistic & 143.0525 & Durbin-Watson stat & 1.803046 \\
Prob(F-statistic) & 0.000000 & & \\
\hline \hline
\end{tabular}

The third hypothesis test results of study showed that since the probability of $F$ statistics in the regression model of second hypothesis is 0.000 and less than 0.05 , therefore, the fitted regression model is significant at the $99 \%$ level of confidence. The average coefficient is approximately equal to 1.8, which shows the variation at included in the regression model assumptions is described linearly, and only $69 \%$ of the variability is explained by the independent variables in the third hypothesis. Sign of the coefficient related to intercept is negative, which means among the control variables, sign of the coefficient related to firm leverage is negative, and with rise in firm debts, the number of daily stock transactions reduces. On the other hand, the dependent variable of daily stock turnover rate has a positive and significant linear relationship in 0.05 levels and the variable of profitability opportunities (MTB). The daily stock turnover rate in the multiple regression analysis does not have a significant linear relationship with the variables of, firm size (SIZE) at 0.05 level and profitability opportunities (MTB) at 0.10 levels. The number of daily transactions of shares in the multiple regression analysis showed a significant linear relationship with the variables of voluntary disclosure (VD). The third hypothesis test Regression analysis indicated that the third hypothesis is that since the probability of voluntary disclosure amplitude and frequency of the t-statistics of daily stock transactions is 0.71 and is higher than significant level of 0.05 , so the third research hypothesis is rejected. In other words, there is no significant relationship between the amplitude of voluntary disclosure and number of daily stock transactions.

\section{Conclusions and Recommendations}

After testing each hypotheses and conclusions about them, now it is turn for overall conclusion. Given that the main objective of this research is to examine the relationship between amplitude of voluntary disclosure and liquidity of shares in Tehran Stock Exchange, the effect of voluntary disclosure of information is examined regarding the proposed Botosan indicators. The summary of results shows that there is not significant relationship between liquidity measures and amplitude of voluntary disclosure, but there is a significant positive relationship between liquidity measures and variables of firm size and firm profitability opportunities. Considering that in hypothesis testing three multivariable regression models is used, test results of research hypotheses show that control variables affect the relationship between independent variables and the dependent variable. Of the control variables, the relationship between liquidity measures and the firm size and profit opportunity variables is positive and significant. According to the summary of the test results, all hypotheses were rejected, so we can conclude that there is no significant relationship between liquidity of shares and amplitude of voluntary disclosure. In this regard, previous research suggests that findings of the research study is consistent with Hariss (1994) and Branch and Freed (1997) overseas and with results of Setayesh et al. (2011) inside the country. However, it is inconsistent with results of Matolscy et al. (2004) who confirmed a negative relationship between disclosure and liquidity of shares. It is also inconsistent with findings of Diamond and Verrecchia (1991) and Espinosa et al. (2008) who confirmed the existence of a direct relationship between disclosure and liquidity. In this regard, the theoretical framework of prior research in the country state that finding of this research is inconsistent with Fakhari and Mohammadi (2010). Fakhari and Mohammadi (2010) in a study examined the impact of information disclosure on the liquidity of the shares of the companies listed on the Stock Exchange of Tehran. Results showed a significant negative relationship between disclosure and liquidity stocks. 


\subsection{Recommendations}

After conducting stages of a scientific research, if the research is done in a systematic process, the researcher can also comment on the findings and results of research and strategies and recommendations to improve future studies. Thus, at the following, recommendations for future research are provided.

According to the results of this study, it seems that the role of voluntary disclosure in Tehran Stock Exchange regarding the Company's liquidity of shares is very weak. Therefore it is recommended that:

1 - Users of financial statements need to know limited disclosure of financial information in a company does not ensure the quality of information and reducing information asymmetry and thus does not provide increased liquidity of shares. But disclosure of financial information by managers and shareholders is not enough to measure liquidity of shares.

2 - Greater disclosure of information about companies' shares should be conducted so that financial users, regarding monetary volume of daily transactions of shares and average daily turnover of shares, ensure that they have adequate information in this regard.

3 - The Stock Exchange applies an integrated system to evaluate the amplitude of the disclosure of financial information about listed companies.

\subsection{Recommendations for future research}

1 - The sample of this research consists of all industries; it is recommended that additional research be conducted to differentiate the types of industries.

2 - It is suggested in another study, the relationship between voluntary disclosure and competition in product market is examined.

3 - Examining the relationship between ownership concentration and liquidity measures of shares in industry individual groups in the Tehran Stock Exchange.

4 - To use other proposed methods, such as the difference between bid and offer prices of stocks, absolute and relative gaps to measure the liquidity of shares.

5 - Examining this research using financial information of companies operating in the meta-exchange market.

\section{References}

Agarwal, P., (2008). "Institutional Ownership and Stock Liquidity." working paper, Available athttp://ssrn.com/.

Akerlof, G., (1970), "The market for lemons quality uncertainty and the market mechanism", Quarterly Journal of Economics, vol. 90, pp. 629-650.

Amihud, Y., Mendelson, Haim and Pedersen, Lasse Heje. (2005). "Liquidity and Asset Prices", Foundations and Trends in Finance, No. 1, PP. 269-364.

Amihud, Yakov, (2002). Illiquidity and stock returns: Cross-section and time-series effects, Journal of Financial Markets 5, 31-56.

Barkli et al., (2002). Liabilities, Liquidity and Cash Management. Wielly, ISBN: 978-0-471-10630-2, p 336.

Bekaert, G., Harvey, C.R., Lund lad, C., (2007). Liquidity and expected returns: lessons from emerging markets. Rev. Finance. Stud. 20, 1783-1831.

Belkaoui, A. (2000), Accounting Theory, Business Press: London, p 140.

Botosan, C.A. (1997), Disclosure level and the cost of equity capital, The Accounting Review, Vol.72, No.3, pp.323-349.

Branch, B., Freed, W., (1997). Bid-ask spread on AMEX and the big board. Journal of Finance 32, 159-163.

Butler, A.W., Grullon, G., Weston, J.P., (2005). Stock market liquidity and the cost of issuing equity. J. Finance. Quant. Anal. 40, 331348.

Cormier, D. and M. Magnan. (1999), An Examination of Social and Environmental Reporting Strategies, Accounting, Auditing \&Accountability Journal, Vol.14, no.5, pp.587-616.

Diamond, D. and Verrecchia, R. (1991), "Disclosure, liquidity, and the cost of capital", The Journal of Finance, Vol. 46 No. 4, pp. 132559.

Espinosa, M. and Trombetta, M. (2007). Disclosure Interactions and the Cost of Equity Capital: Evidence from the Spanish Continuous Market. Journal of Business Finance \& Accounting, Vol. 34, No. 10, pp.1371- 1392.

Fakhari, H., FallahMohammadi, N. (2009). Examining the effect of information disclosure on the liquidity of the shares of the listed companies in Tehran Stock Exchange. Accounting Research, First Year, No. IV, pp. 148-163.

Frieder and Martell. (2006). "On Capital Structure and the Liquidity of a Firm's Stock", www.ssrn.com.

Hariss, L., (1994). "Minimum price Variations, discrete bid ask spread, and quotation sizes", Review of financial studies 7, 149-178.

Hendriksen, E.S. and Van Breda, (1992).Edition. United States of America, Accounting Theory. pp. 115-119.

Karthik Balakrishnan, Mary Billings, Bryan Kelly, Alexander Ljungqvist, (2013), "Shaping Liquidity: On the Causal Effects of Voluntary 
Disclosure", Journal of Finance, Forthcoming. NBER Working Paper No. 18984.

Kashanipoor, M., Rahmani, A., and Parchini, M., (2009). The relationship between voluntary disclosure and non-responsible managers. Studies, accounting and auditing, Volume 16, No. 57:85-100.

Marc L. Lipson and Sandra Mortal, (2009), "Liquidity and Capital Structure ", Journal of Financial Markets, Forthcoming, Darden Business School Working Paper.

Matolcsy S.L.Z., \& Chow D. (2007) the Association between Board Composition and Different Types of Voluntary Disclosure», European Accounting Review; 16(3): 555-583.

Rouwenhorst, K.G., (1998). International momentum strategies. The Journal of Finance 53, 267-284.

Setayesh, M, Kazemnejad, M., and Zolfaghari, M. (2011).Examining the effect of disclosure quality on liquidity of shares and capital costs of companies listed in Tehran Stock Exchange. Journal of Accounting Research, No. 3, PP 55-74.

Welker, M., (1995).Disclosure policy, information asymmetry and liquidity in equity markets. Contemporary Accounting Research 11 , 801-828.

Wolk, Dodd, Tearny. (2001), "Accounting theory", Second Edition, p 52.

Yahiazadehfar, M., and Khorramdin, J. (2008). The role of liquidity and liquidity risk on excess stock returns on the Tehran Stock Exchange. Accounting and Auditing Review, No. 53, pp. 101-118. 